\title{
La fortificación de Évora durante la Guerra de Restauración portuguesa: discusiones y desacuerdos
}

\author{
The Fortification of Évora during the Portuguese Restoration War: \\ Discussions and Clashes
}

\author{
ANA TERESA DE SOUSA \\ HERITAS, CIDEHUS, Universidad de Évora \\ aana_sousa@hotmail.com
}

\begin{abstract}
Resumen: La Guerra de Restauración portuguesa (1640-1668) impuso la necesidad de proteger la frontera alentejana, recurriendo para ello a la reforma de las antiguas defensas castrenses y al desarrollo de nuevos proyectos de fortificación. En este contexto, se distingue el caso de la fortificación de la ciudad de Évora, en el Alentejo. Esta fortificación fue una de las más problemáticas de la época, debido a cuestiones de proyección y en cuanto a la resolución de las obras. Destacaría el trabajo de algunos ingenieros militares franceses que realizaron proyectos de fortificación para la ciudad, con especial énfasis en el enfrentamiento entre el ingeniero militar Pierre de Saint-Colombe y el tratadista portugués Luís Serrão Pimentel. Analizaré todo lo dicho cotejando documentos del Archivo Nacional de la Torre do Tombo y de la Biblioteca de Ajuda, en Lisboa, en la Biblioteca Pública de Évora y en la Biblioteca Nacional de España.
\end{abstract}

Palabras clave: Évora, fortificación, Guerra de Restauración, desacuerdos, proyectos.

\begin{abstract}
The need for the Portuguese Restoration War arose between 1640 and 1668, becoming imperative the defense of the Alentejo border through the adaptation of the old military defenses and the elaboration of new projects. In this context, the case of the fortification of Évora, in the Alentejo province, stands out. This fortification was one of the most problematic at the time, in terms of projection and the resolution of the works. The influence of some French military engineers who made fortification projects for Évora should be highlighted, giving special focus to the case of the confrontation between the military engineer Pierre de Saint-Colombe and the Portuguese treatise Luís Serrão Pimentel. These analyses will be made from original documentation existing in the National Archive of Torre do Tombo and in the Library of the Ajuda (Lisbon), in the Public Library of Évora, and in the National Library of Spain (Madrid).
\end{abstract}

Keywords: Évora, fortification, Portuguese Restoration War, discussions, projects. 
Introducción

En vísperas de la Guerra de Restauración portuguesa (1640-1668), la defensa de la frontera entre Portugal y España constituía una preocupación constante para los monarcas. En el caso portugués, destaca la reestructuración de las fortificaciones del Alentejo ${ }^{1}$, con el objetivo de formar un proyecto de defensa unificado ${ }^{2}$. En este sentido, sobresaldrían varios proyectos para la defensa de la ciudad de Évora.

Con el ascenso al trono del rey João IV, en diciembre de 1640, se fortalece la idea de la creación de un ejército permanente y de unos órganos auxiliares, así como la creación del Consejo de Guerra y de la Junta de la Frontera, con funciones bien definidas, entre ellas las de inspeccionar y tratar todas las cuestiones relativas a las fortificaciones ${ }^{3}$. Estos órganos actuarán según una nueva geografía política, administrativa y militar, y se crearán provincias militares, siendo la del Alentejo la más grande y vulnerable por sus características topográficas, pues la mayor parte de su extensión es llana4.

Aparte de la estrategia de los asuntos de naturaleza militar, en el Consejo de Guerra se debatía además acerca de la gestión de los fondos recaudados para la guerra y sobre el dinero para el pago de los salarios de los soldados ${ }^{5}$.

Por lo tanto, se proyectó una concentración de plazas fuertes y se otorgó prioridad al refuerzo defensivo de ciudades del interior, como Évora. A esta concentración también correspondió una nueva tipología constructiva, con diversas intervenciones, desde el recinto de Elvas a la concentración de puntos defensivos más pequeños, desde fuertes a fortines, variando de acuerdo con la prioridad de ataque del enemigo.

Sin embargo, este refuerzo de La Raya implicaba requisitos técnicos, lo que llevaría a la necesidad de mejorar la formación de los maestros portugueses, labor asumida por el ingeniero jefe del reino Luís Serrão Pimentel, el cual destacaba en el ámbito de la fortificación. Fue, sobre todo, teórico y tratadista, y recurrió en sus conceptos a eruditos de referencia, tales como Adam Fretag, Mathias Dogen, Goldman, Coheorn y Marolois ${ }^{6}$. Basaba su formación en la teoría de los conceptos de fortificación, en la que se daba prioridad al foso, a la manera holandesa; en la

\footnotetext{
${ }^{1}$ Da Conceição, Margarida Tavares, "Configurando a praça de guerra: o espaço urbano no sistema defensivo da fronteira portuguesa", en Rossa, Walter et al. (coords), Actas do Universo Urbanístico Português: 1415-1822, Lisboa, Comisión Nacional para la Conmemoración de los Descubrimientos Portugueses, 2001, p. 827.

${ }^{2}$ De Sousa, Ana Teresa, "La frontera del Alentejo durante la Guerra de Restauración”, en Revista Historia Autónoma, 12 (2018), pp. 103-104.

${ }^{3}$ Ibídem, p. 101.

4 "Descrição de Portugal que tem por principal assunto falar de suas praças", Biblioteca Pública de Évora [BPE en adelante], Fundo Manizola, Cod. 509-1, ff. 6-8.

${ }^{5}$ Gama, Maria Luísa, O Conselho de Estado no Portugal Restaurado - Teorização, Orgânica e Exercício do Poder Político na Corte Brigantina (1640-1706), tesis de máster, Universidad de Lisboa, 2011, p. 80.

${ }^{6}$ Fialho Conde, Antónia et al., "A costa algarvia três séculos depois - o olhar entre a Geografia e a História", en $I V$ Simpósio Luso Brasileiro de Cartografia Histórica, Porto, 9-12 de noviembre de 2011, p. 3 «http://eventos.letras. up.pt/ivslbch/comunicacoes/104.pdf) ' [consultado el 21 de mayo de 2018].
} 
importancia del cálculo y de la práctica, a través de estudios y representaciones matemáticas y de geometría pura, así como de los perfiles e iconografía de las fortificaciones; y daba primacía también a la defensa y evolución técnicas de los baluartes. De esta manera, Luís Serrão Pimentel incorporó a la cultura portuguesa el modelo de fortificación de los holandeses a través de profundos estudios. Esto le permitiría enseñar ciencia militar, matemática y cosmografía en el Aula Militar en 1641, por determinación del Consejo de Guerra de 1640 y de la Junta de Fortificaciones, órganos que monopolizaban la enseñanza y la supervisión de los asuntos y cuestiones militares.

Gracias a su aptitud y desempeño, Luís Serrão Pimentel logró la creación de la Escuela de Matemáticas y Fortificación de la Ribeira das Naus, en $1647^{7}$. Esta fue la primera escuela de educación militar especializada en Portugal y representaba la institucionalización de la ingeniería militar en el contexto portugués, pues hasta entonces quienes trataban las fortificaciones eran mayoritariamente ingenieros militares extranjeros ${ }^{8}$, en su mayoría de nacionalidad francesa 9 . Serrão Pimentel, muy centrado en su trabajo de enseñanza, no tardó en sobresalir entre los ingenieros militares por sus especiales nociones sobre las fortificaciones militares, ayudando a la teoría con la práctica ${ }^{10}$.

Luís Serrão Pimentel fue también el autor del Methodo Lusitânico de Desenhar as fortificações das Praças Regulares e Irregulares fortes de campanha, e outras obras pertencentes à Arquitectura Militar, de 1680. El título de Methodo Lusitânico se relaciona con el hecho de que Serrão es el primero en hablar en lengua portuguesa acerca de esta cuestión, introduciendo un nuevo método de fortificación en Portugal, el cual se basaba en los métodos holandeses y en su enseñanza recibida de los jesuitas, dando prioridad a las cuestiones matemáticas de las fortificaciones.

Sin embargo, Serrão Pimentel también destaca en términos prácticos. Participó en las batallas de las líneas de Elvas, en 1659, y Ameixial, en 1663. En 1662, viajó al Alentejo en tres ocasiones con el fin de llevar a cabo el plan de fortificación de Évora ${ }^{11}$, participando en el proyecto del Baluarte de São Bartolomeu.

Es en esta coyuntura en la que debe analizarse el caso de Évora, examinando para ello la Resposta Apologética do Tenente General Pedro de Santa Colomba em defensão da sua planta de Evora ao papel de Luiz Serrão Pimentel Lente de Mathematica, con fecha de 26 de diciembre de $1661^{12}$.

\footnotetext{
${ }^{7}$ Martins Ferreira, Alexandre, Luís Serrão Pimentel (1613-1679): Cosmógrafo Mor e Engenheiro Mor de Portugal, tesis de máster, Facultad de Letras de Lisboa, 2009, p. 79.

${ }^{8}$ Fialho Conde, Antónia, "A costa algarvia...", p. 3

${ }^{9}$ De Sousa, Ana Teresa, "La frontera del Alentejo... op. cit., p. 105.

${ }^{10}$ Sousa Viterbo, F.M., Dicionário Histórico e Documental dos Arquitectos, Engenheiros e Construtores Portugueses, Lisboa, Imprensa Nacional Casa da Moeda, Vol. II, 1899, p. 271.

${ }^{11}$ Arquivo Nacional Torre do Tombo [ANTT en adelante], Registo Geral de Mercês de D. Afonso VI, livro 11, $85 \mathrm{v}-88 \mathrm{v}$

${ }^{12}$ Biblioteca de Ajuda [BA en adelante], 51-VI-1, ff. 93-96.
} 


\title{
1. La ciudad de Évora y su fortificación
}

En el año de 1640, aprovechando el movimiento de tropas y las atenciones puestas en la sublevación de Cataluña, algunos nobles y eruditos portugueses se rebelaron contra el dominio castellano en Portugal ${ }^{13}$. Esta revuelta culminaría con la independencia de Portugal materializada en la proclamación del duque de Bragança, quien reinará como João IV. Esta proclamación iba a coger por sorpresa no solo a los representantes políticos de Felipe IV en Portugal, sino también a la propia monarquía castellana ${ }^{14}$.

\begin{abstract}
Sabbado primeiro de Decembro de 640 (...) a nobresa da Cidade de Lisboa, pera remedio da ruina em que se via, \& ao Reyno todo, aclamou por Rey o Duque de Bragança Dom João Principe benigníssimo, magnanimo, fortíssimo, piadiaso, prudente, nos trabalhos incansável, no governo atentado, no amor da republica cuidadoso, de seu acrescentamento ardentíssimo, \& vigilante, legitimo sucessor do Imperio Lusitano ${ }^{15}$.
\end{abstract}

Después de haber sido proclamado rey de Portugal João IV, el 1 de diciembre de 1640, "y hallándose el Reino destituido de los que se requerían para su conservación"16, una de las primeras actuaciones preventivas a efectuar era la refortificación de la frontera del Alentejo, en la cual se situaba la ciudad de Évora, por ser distante doce leguas de La Raya, y de la que el gobierno de aquel tiempo no se olvidó. Évora era capaz de albergar a los pueblos vecinos y a los residentes de los más débiles lugares de la provincia cuando fuese necesario en caso de un excesivo poder del enemigo en términos de táctica y avance ${ }^{17}$.

Según Saint-Colombe, antes de su proyecto, ya el ingeniero militar francés Charles Lassart había hecho un diseño con baluartes de dimensiones muy altas, con capacidad para albergar una gran guarnición, y cortinas que se situaban entre esos baluartes ${ }^{18}$ "sin valerse de los muros antiguos, pareciéndole que podría conseguir su intención"19.

\footnotetext{
${ }^{13}$ Oliveira, António de, Movimentos Sociais e Poder em Portugal no Século XVII, Coimbra, Instituto de Historia Económica y Social de la Facultad de Letras de la Universidad de Coimbra, 2002, p. 11.

${ }^{14}$ Soares da Cunha, Mafalda, "O significado da «Restauração»", en Matos, Artur Teodoro de (coord.), Memória de Portugal-o milénio português, Lisboa, Circulo de Leitores, 2001, p. 355.

${ }^{15}$ Pais Viegas, António, Manifesto do Reyno de Portugal, no qual se declara o direyto, as causas, \& o modo, que teve para exemirse da obediência del Rey de Castella, \& tomar a voz do Serenissimo Dom Joam IV do nome, XVIII entre os reys verdadeyros deste Reyno, Biblioteca Nacional de España [BNE en adelante], R/25149(22), s.f.

${ }^{16}$ Traducido del original BA, 51-VI-1, f. 93.

${ }^{17}$ Ibídem.

${ }^{18}$ De Sousa, Ana Teresa, O Conjunto Abaluartado de Évora, Faro, Sílabas \& Desafios, 2015, pp. 172 y 175 ; De Sousa, Ana Teresa, "Saint-Colombe y Luís Serrão Pimentel: Debates y Confrontaciones", en Gajate Bajo, María y Laura González Piote (eds.), Guerra y Tecnología: interacción desde la Antigüedad al Presente, Madrid, Fundación Ramón Areces, 2017, p. 212; Serrão Pimentel, Luís, Methodo Lusitanico de desenhar as fortificações das praças regulares e irregulares fortes de campanha, e outras obras pertencentes à arquitetura militar, Lisboa, Imprensa de António Craesbeeck de Mello, 1680, p. 44.

${ }^{19}$ Traducido del original BA, 51-VI-1, f. 93.
} 
A finales de 1648, se encontraría en Évora otro ingeniero militar francés, Nicolau de Langres, bajo las órdenes de André de Albuquerque, general de artillería del Alentejo. Gracias a ambos se inició en 1651 la construcción de algunos baluartes. Sin embargo, con la muerte el día 15 de mayo de 1653 del príncipe Teodosio, generalísimo de las armas del reino, se detendrían los estudios y trabajos iniciales, estancándose el tema de la defensa de la ciudad ${ }^{20}$.

La reina viuda, Luísa de Gusmão (1613-1666), se vio obligada a nombrar generalísimo de las armas del reino a su otro hijo, el futuro rey Afonso VI. En este período estallaba el primer ataque de los castellanos, bajo el mando del duque de San Germán; su escenario se situaría en la plaza fuerte de Olivenza, en abril de $1657^{21}$, por lo que se consideraba urgente fortificar las localidades del Alentejo.

En ese mismo período, una carta de la reina viuda, Luísa de Gusmão, con fecha de 1 de abril de 1657, expresaba el deseo de ver la ciudad de Évora fortificada, debiendo recomenzarse las obras de su fortificación ${ }^{22}$.

Por lo tanto, Langres se comprometió a desempeñar la tarea de hacer frente a la nueva fortificación de la ciudas. Fue él quién elaboró un plan de emergencia, con baluartes adosados a las cortinas y con la existencia de algunas obras externas avanzadas ${ }^{23}$. Estas tendían a hacerse frente a la parte más débil de la plaza para evitar la aproximación del enemigo ${ }^{24}$.

Después de que Langres se aliara con el enemigo, en $1662^{25}$, "la falta del tiempo y agravado el estado de la guerra con la pérdida de Olivenza y Arronches, con el aumento del dinero aplicado, se volvió a intentar en dicha obra de fortificación de Évora"26. El conde de Atouguia encargó a Simon Jouquet y a Jean Brivois, "que estaban en la provincia", el diseño de un nuevo proyecto para la fortificación de la ciudad. Pero este se consideró inaplicable debido a razones técnicas, por "excesivo gasto monetario y de tiempo"27, encargando a Saint-Colombe una nueva planta "con el tiempo y el dinero disponible"28, donde dominaban las obras externas que defienden los baluartes de la fortificación ${ }^{29}$, denominadas medias lunas o revellines ${ }^{30}$. A raíz de su proyecto, Saint-Colombe declararía que:

[...] havendo feito a que apresentei ao Conselho de Guerra com aplauso de muitos, comunicou se por ordem do mesmo Conselho a Luiz Serrão Pimentel, o qual com razões de Escola, e seguindo em parte algum autor dos mais antigos

\footnotetext{
$\overline{{ }^{20} \mathrm{BPE}, \mathrm{CXXII} / 1-12}$ d., f. 173a (suelto).

${ }^{21}$ Sousa Lobo, Francisco, "Batalhas da Restauração", en Revista Monumentos, 7 (1997), p. 84.

${ }^{22} \mathrm{BPE}, \mathrm{Amr}^{\circ} \mathrm{x}, \operatorname{cod} .1^{\circ}, \mathrm{n}^{\circ} 18$, Livro verde, f. 51.

${ }^{23} \mathrm{BA}, 51-\mathrm{VI}-1$, f. 93.

${ }^{24}$ BA, 51-VI-26 (132), f. 29. De Sousa, Ana Teresa, "Saint-Colombe y Luís Serrão Pimentel... op. cit., p. 212.

${ }^{25}$ De Sousa, Ana Teresa, "La frontera del Alentejo... op. cit., p. 119.

${ }^{26}$ Ibidem.

${ }^{27}$ Ibídem.

${ }^{28}$ BA, 51-VI-1, f. 93.

${ }^{29}$ Serrão Pimentel, Luís, Methodo Lusitanico... op. cit., pp. 40-41; De Sousa, Ana Teresa, "Saint-Colombe y Luís Serrão Pimentel... op. cit., p. 213.

${ }^{30}$ BA, 51-VI-1, f. 93. Sousa Viterbo, Dicionário Histórico... op. cit., vol. III, pp. 11-12.
} 
desta arte, e em tudo seu espirito de contradição, como o tem feito sempre contra os desenhos obrados neste Reyno por engenheiros de fama ${ }^{31}$.

Pero, en febrero de 1663, Évora era una gran ciudad con fortificación debilitada, por no tener más que las antiguas murallas, y en ruinas. En aquel momento, el conde de Vila Flor creía que habría muchos impedimentos a dicha fortificación y un gasto mayor si se pospusiera el proyecto, "y para aprovecharse la tierra que estaba levantada en diferentes partes, cuando por diferentes veces se intentó fortificar esta Ciudad, tenía la misma dificultad de gasto de tiempo, y dinero, $[\ldots]$ trató de poner todo el cuidado en perfeccionar esta plaza"32.

Cuando los castellanos conquistaron Évora, el 19 de mayo de 1663, comenzaron por aprovechar las ventajas de las construcciones que los portugueses habían dejado. Invirtieron sobre todo en la continuación de la construcción del fuerte de Santo António, "que pronto empezaron a poner a la perfección", recurriendo al trabajo de los residentes de la ciudad, "que como cautivos trabajaron en él" 33 .

Según el maestro de campo del Alentejo João da Costa, en 1644, la fortificación de Évora mostraba errores desde el inicio de su construcción, pues se habían hecho gastos excesivos, que no justificaban lo que se había construido. Esto explica las regresiones realizadas en dicha fortificación a lo largo del tiempo de guerra. Acabado el dinero, acabó el fervor de su construcción ${ }^{34}$.

\section{Respuesta apologética de Saint-Colombe a Luís Serrão Pimentel: 26 de diciembre de 1661}

Como he mencionado, a Saint-Colombe se le encomendó el plan de fortificación de la ciudad de Évora, donde dominaban las medias lunas. No obstante, tras presentarlo al Consejo de Guerra, fue rechazado debido a la muy desfavorable opinión de Luís Serrão Pimentel ${ }^{35}$, el cual efectuó las siguientes objeciones:

Objeción 1: Que las medias lunas son parte esencial de una fortificación, no pudiendo separarse de sus cortinas.

\footnotetext{
${ }^{31}$ BA, 51-VI-1, f. 93.

${ }^{32}$ Alvares da Cunha, Antonio, Aplauzos académicos e rellação... Traducido del original [BNE], 1673, R/38624, ff. 11-12.

${ }^{33}$ Ibídem, f. 27.

${ }^{34}$ Marinho Azevedo, Luís de, Commentarios dos valerosos feitos, qve os portvgvezes obraram em defensa de sev Rey, \& patria na guerra de Alentejó. Que continuava o Capitaõ Luis Marinho d'Azevedo, governando as armas da mesma Provincia [BNE], 1644, 2/61347, f. 10.

${ }^{35}$ Sousa Viterbo, Dicionário Histórico ... op. cit., vol. III, p. 12.
} 
Objeción 2: Que la mayoría de sus medias lunas tiene ángulos de 60 grados que pueden ser fácilmente dañados por las baterías enemigas.

Objeción 3: Que el perfil presentado no es digno, y que el foso no tiene más que cinco pies de fondo, lo que es muy poco para una defensa eficaz.

Objeción 4: Que siendo los muros de piedra y barro es notorio que van a arruinar, siendo de poca resistencia.

Objeción 5: Que no considera en las medias lunas los defectos que apunta en las obras coronas, y que lo que alega de Tarragona no confiere con su historia, debiendo autorizar el proyecto, con autores dignos para que se le dé crédito. Por fin, era indigno su plan para la fortificación de Évora. ${ }^{36}$

Según Luís Serrão Pimentel, el proyecto era poco digno debido a su perfil incorrecto, careciendo el foso de profundidad y presentando las medias lunas poca resistencia. De hecho, Saint-Colombe apostaba por un modelo similar al de Barcelona, con medias lunas. Por su parte, Luís Serrão Pimentel, inspirándose en la Escuela Holandesa y en la formación que había recibido de los jesuitas, buscaba la aplicación de los principios de la geometría y de las matemáticas, basando sus objeciones en los autores antiguos mencionados anteriormente. Además, esa conjugación era hecha según los Elementos de Euclides, basada en los estudios de matemática de los jesuitas, complementados con geometría aplicada a la geografía y a la astronomía ${ }^{37}$.

En defensa de su plan, Saint-Colombe respondió a las objeciones por escrito en la Resposta Apologética, pues según él "la escritura alcanza más que las palabras"38. SaintColombe afirmaba que, en relación con las medias lunas, algunos autores antiguos más teóricos que prácticos las habían reprobado, "porque aún no estaba aprobado su préstamo y utilidad con la experiencia, que es la única maestra de las cosas de guerra" ${ }^{\prime 3}$. Por el contrario, los autores modernos y los soldados hicieron gran estima de las medias lunas por las "grandes ventajas que confieren en la defensa de las plazas" ${ }^{40}$. Lo justifica afirmando que:

Groto as prefere aos mesmos baluartes nas praças [...]. O livro do P. Fornier traduzido por Manoel Fernandes Vila Real no qual se contem os modos de fortificar dos mais celebres autores de todas as nações, diz o que se segue: "alguns repruevan las media luas y rebelines, pero la esperiencia muestra su grande utilidade, pues una sola media luna en Bolduque fue causa de dilatar se mucho aquel celebre sitio, y aun Groto en su fortificacion las prefiere a los baluartes, querendo que una placa sea mas fuerte com aquellas pieças separadas del cuerpo principal. Yo he visto el desígnio de una placa imitando a Tancino de quien lo avia tomado Groto, hecho com tanto artificio, que por el intervalo daquelas medias lunas y rebelines se defendiam y flãqueavam todas, de sinco, seis y mas flancos, siendo que la placa no tenia baluartes".

\footnotetext{
${ }^{36}$ Traducido del original. BA, 51-VI-1, f. 93v-95.

${ }^{37}$ Dias, Nuno et al., "Influência dos jesuítas no ensino em Portugal", en Llull, Revista de la Sociedad Española de Historia de las Ciencias y de las Técnicas, 35, 75 (2012), p. 114

${ }^{38}$ Ibídem, f. $93 \mathrm{v}$.

${ }^{39}$ Ibidem.

${ }^{40}$ Ibídem.
} 
Outros autores relatam e encarecem as mesmas prerrogativas das meias luas cujas razões não allego [...] por que entendo que em semelhante matéria é mais acertado fundar-se na experiencia dos sítios, que sobre quantos autores escreveram, por serem os mais delles pouco ou nada soldado. ${ }^{41}$

Según Saint-Colombe, en las últimas guerras de las diversas naciones de Europa, las medias lunas habían sido muy útiles, suponiendo en algunos casos la garantía de salvación de las plazas. El hecho de tratarse de una obra exterior, apartada del cuerpo de la plaza, permitía reaccionar y recuperarse tras una embestida: "ha sucedido en varias ocasiones recuperarse una y muchas veces, medias lunas ya tomadas por el enemigo en razones del gran trabajo y dificultad que tiene el alojarse en ellas, por ser dominadas por la plaza"42.

Saint-Colombe nos muestra algunos ejemplos de cómo las medias lunas fueron eficaces o no en la defensa de las plazas. Comienza haciendo referencia al caso de Milán, donde los castellanos habían diseñado medias lunas en la fortificación.

Sitiou o Duque de Crequi em 636 em nome de El Rey chritianissimo junto com
os de Saboya e de Parma, Valença de Pó na raia do estado de Milão com 24.000
infantes e 5.000 cavallos achando-se aquella praça com muros e torriões
antigos de pouca resistencia; os castelhanos á vista de tão poderoso exercito a
fortificaram com meias luas desapegadas de terras pequenas e imperfeitas por
não dar o tempo lugar a mais, e sendo ellas desta qualidade e o exercito qual
disse, depois de se verem os francezes obrigados a buscar estas meias luas com
aproches, quatro meses de opugnação, perda de muita gente, muitos dares e
tomares, levantaram o sitio, e destruíram tão florente exercito em tão limitada
empresa como sabe toda a Europa. ${ }^{43}$

Saint-Colombe continúa comparando la proyección de las medias lunas en Badajoz y Valencia de Alcántara con las de Tarragona. Según él, las primeras eran débiles y de poca resistencia, siendo, sin embargo, fuertes y sólidas en Tarragona.

[E]m Badaios levantou o inimigo á nossa vista as mesmas meias luas ao redor da praça por traça de homens dos mais peritos, e soldados do tempo; e no ultimo sitio que posemos a Valença d'Alcantara na campanha de Olivença uma meia lua de pedra e barro que cobria os muros e incluía um convento, nos fez perder a empresa, sendo que chegamos a lhe pôr baterias que não obravam nada, e arrimar mineiros ao pé da mesma meia lua.

Tarragona está fortificada nesta forma e as meias luas são de pedra e cal. ${ }^{44}$

En respuesta a la primera objeción de Luís Serrão Pimentel acerca de la ejecución de medias lunas en el proyecto de fortificación de Évora, Saint-Colombe argumentaba que estas

\footnotetext{
${ }^{41}$ BA, 51-VI-1, f. $93 \mathrm{v}-94$.

${ }^{42}$ Ibídem, f. 94.

${ }^{43}$ Ibídem, 94v.

${ }^{44}$ Ibidem, fl. 94v-95.
} 
eran una parte fundamental de la fortificación, pues las medias lunas se defendían bien entre ellas, permitiendo una mayor protección de la plaza fuerte:

Objeción 1: Que las medias lunas son parte esencial de una fortificación, no pudiendo separarse de sus cortinas.

Defensa 1: Que las medias lunas se defienden unas a otras, oblicuamente, conforme es la línea del recinto de los muros más o menos curva; se defienden de los muros con artillería y mosquetería por línea rasante desde las baterías que $[\ldots]$ no serán vistas por el enemigo, sino asomado sobre la explanada y contraescarpa $[\ldots]$; se defienden por línea fija de otro gran lance de muros; algunas se defienden con flancos legítimos con capacidad de artillería como los baluartes; y otras se defienden con flancos bajos corridos desde el frente de las medias lunas hasta la barbacã $\left[\ldots .{ }^{45}\right.$

La segunda objeción de Serrão Pimentel hacía referencia al hecho de que la mayoría de sus medias lunas en Évora tenían los ángulos de $60^{\circ}$, siendo fácilmente cortadas por las baterías enemigas.

En respuesta, Saint-Colombe contraatacaba señalando que esto constituía un inconveniente menor porque así se facilitaba una defensa recíproca con las demás.

Objeción 2: Que la mayoría de sus medias lunas tiene ángulos de 60 grados que pueden ser fácilmente dañados por las baterías enemigas.

Defensa 2: Que el menor inconveniente es tener los ángulos de 60 grados de lo que no están bien defendidas las medias lunas, y que siendo así agudas dan recíproca defensa unas a otras [...], y no me mostrará Luíz Serrão Pimentel que semejantes ángulos cómo lo son todos los de las plazas de cuatro baluartes, y otros muchos en plazas irregulares se dispusieran con la facilidad que dice. ${ }^{46}$

Luís Serrão Pimentel señalaba también que el perfil de la fortificación de Évora resultaba extraño para los conceptos de la ingeniería militar, y que el foso no tenía más de cinco pies de profundidad, muy escasos para la defensa de la plaza.

Saint-Colombe, por su parte, argumentaba que el perfil de su obra resultaba altamente operativo ya que el parapeto era más sólido que el del modelo preconizado por Pimentel.

Objeción 3: Que el perfil presentado no es digno, y que el foso no tiene más que cinco pies de fondo, lo que es muy poco para una defensa eficaz.

Defensa 3: Si Luiz Serrão Pimentel consideró bien la variedad de los perfiles que hacen los autores, y los que realmente se concretan casi en todas las plazas de Europa, no sólo no creerá que es el mío fuera de arte, sino que se prefiere a todos los más, y particularmente en la práctica de dichas plazas [...] y es evidente que es de este modo mucho más fuerte el parapeto porque lo acogen los tiros en pleno, estando en todas sus partes a prueba de los tiros del enemigo;

\footnotetext{
${ }^{45}$ Traducido del original. Ibídem, fl. 93v y 95.

${ }^{46}$ Ibídem.
} 
lo que no tiene el proyecto que sigue Luiz Serrão Pimentel, porque para descubrir la contraescarpa y foso cae en el inconveniente de hacer el ángulo del parapeto demasiado agudo en cima, que pocos tiros bastan para arruinarlo $[\ldots] \cdot{ }^{47}$

Además, Saint-Colombe indicaba que, aunque en su perfil no había dado más de cinco pies de profundidad al foso, esto no constituía impedimento para añadir más profundidad al mismo, y nadie ignoraba que cuanto más hondos eran los fosos, mejor eran defendidos los laterales de los baluartes de la fortificación. Era el caso de Floriana de Malta, cuyo foso tuvo escasa profundidad en sus inicios, pero que entonces ya contaba con 8 pies de fondo: "por el transcurso de muchos años se le ha abierto en la roca viva ciento y ocho pes de fondo"48.

Luís Serrão Pimentel añadía que, siendo las paredes de piedra y arcilla, se arruinaría muy pronto la plaza al ser de poca resistencia.

Saint-Colombe, en cambio, subrayaba que este tipo de obras, más breves y baratas, todavía eran muy seguras y sólidas.

\footnotetext{
Objeción 4: Que siendo los muros de piedra y barro es notorio que van a arruinar, siendo de poca resistencia.

Defensa 4: Digo que he alcanzado por experiencia que las obras de piedra y barro son buenas, más breves y más baratas [...], y no dejan de ser muy seguras siendo bien obradas $[\ldots]{ }^{49}$
}

Por último, Serrão Pimentel subrayaba que Saint-Colombe no contemplaba en las medias lunas los defectos que eran perceptibles en las obras exteriores y que su obra se debía basar en otros autores para que se le diese crédito a su trabajo a lo largos de los años. En última instancia, Serrão Pimentel consideraba el diseño de Saint-Colombe muy indigno para la plaza de la ciudad de Évora, al haber sido realizado por un ingeniero militar con formación francesa, donde la geometría seguía siendo rigurosa según unos planos y modelos de fortificación.

A su vez, Saint-Colombe argumentaba que las medias lunas y las obras exteriores se defendían entre sí de manera muy eficaz, y que su plan era correcto.

Objeción 5: Que no considera en las medias lunas los defectos que apunta en las obras coronas, y que lo que alega de Tarragona no confiere con su historia, debiendo autorizar el proyecto, con autores dignos para que se le dé crédito. Por fin, era indigno su plan para la fortificación de Évora.

Defensa 5: Qué mal puedo considerar en las medias lunas los defectos que noto en las coronas, pues es manifiesto que donde estas sirven después de tomadas al enemigo de un gran alojamiento [...], son las otras destruidas de modo de los tiros de la plaza en todas sus partes inferiores y externas que no puede el

\footnotetext{
${ }^{47}$ Ibídem.

${ }^{48}$ Ibídem.

${ }^{49}$ Ibídem.
} 
enemigo alojarse en ellas, sino derramando mucha sangre y mucho sudor del cuerpo. $^{50}$

De hecho, según Saint-Colombe, Tarragona fue fortificada de una manera similar a su plan de fortificación de Évora, y sus medias lunas se mostraron muy resistentes. Desafortunadamente, su proyecto no existe hoy en día, o al menos no hay conocimiento del mismo. En el documento en sí no está incluido.

Luís Serrão Pimentel también propuso un proyecto para la fortificación de la ciudad de Évora, que pretendía la existencia de diez baluartes y una obra externa. En lugar de la pequeña plaza, cuadrada o pentagonal, que se erigía en el sitio más conveniente de la plaza principal, nombrada ciudadela ${ }^{51}$, él dibujó una obra abierta, cuya defensa era más pequeña: "Propone de nuevo Luiz Serrão Pimentel un plan para la fortificación de Évora, lo cual consta de diez baluartes y una obra corna, y una citadela, obra abierta a la plaza de menos defensa" ${ }^{52}$.

$\mathrm{Su}$ diseño tenía menor perímetro que el plan desarrollado por Saint-Colombe, siendo también más arriesgado, componiéndose por baluartes con dimensiones muy elevadas y capacidad para acoger gran guarnición.

Para su defensa, Saint-Colombe preparó una memoria de justificación que expondría al Consejo de Guerra de Afonso VI, que reinó entre 1656 y 1683, defendiendo puntos de vista contrapuestos al plan de Serrão Pimentel, el cual consideraba una absurdidad pues: "calculando el número de brazas de toda la albañilería por su plan y perfil, viene a ser, veintiséis mil novecientos treinta y dos, sin contar el parapeto de las rondas; y por el computo de mi dibujo, trece mil setecientos veinte y nueve, que es menos de a mitad". El suyo resultaba de menor perímetro, defendiéndose mejor así: "haciéndose paralelo de la suya con la mía, y midiéndose ambas, se vio perfectamente que la mía es de menor circuito; porque, aunque incluyese en la cuenta la ciudadela [...], fuera siempre mucho mayor la circunferencia de su plan"53. Según él:

\footnotetext{
Importam seus terraplenos vinte cinco mil cruzados mais que os da mina planta, a tres reis cada pe cubico alto e baixo, que e a menor preço, sem contar a esplanada que excede a proporção; e suppondo que as paredes de ambos os desenhos se façam de pedra e cal, os seus passarão de quarenta mil cruzados mais, a razão de tres cruzados cada braça, sem contar as paredes da contraescarpa; e se se reducir o meu perfil a um quinto de escarpa, que e o que lhe basta para haver de ser os muros de pedra e cal, se achara ainda muito maior o excesso das braças de uma para outra. ${ }^{54}$
}

\footnotetext{
${ }^{50}$ Ibídem.

${ }^{51}$ Serrão Pimentel, Luís, Methodo Lusitanico ... op. cit., p. 39.

${ }^{52} \mathrm{BA}, 51-\mathrm{VI}-1$, f. 95.

${ }^{53}$ Ibídem.

${ }^{54}$ Ibídem.
} 
Por otra parte, consideraba que este se trataba de un plan poco digno de alguien que había estudiado matemáticas con los jesuitas ${ }^{55}$ y era seguidor de los maestros holandeses de fortificación, habiéndose apropiado, además, del proyecto del ingeniero militar Nicolau de Langres: "no es digno de un maestro de matemáticas, conocido entre los portugueses, el robo del plan de Langres como lo hizo, tomarlo con papel aceitado, ni siquiera tiene el arte para reducir un tercer, cuarto o la mitad, para disimular el robo" ${ }^{56}$ (fig. 1).

Figura 1: Plano de la fortificación de Évora, por Nicolau de Langres, c. 1660.

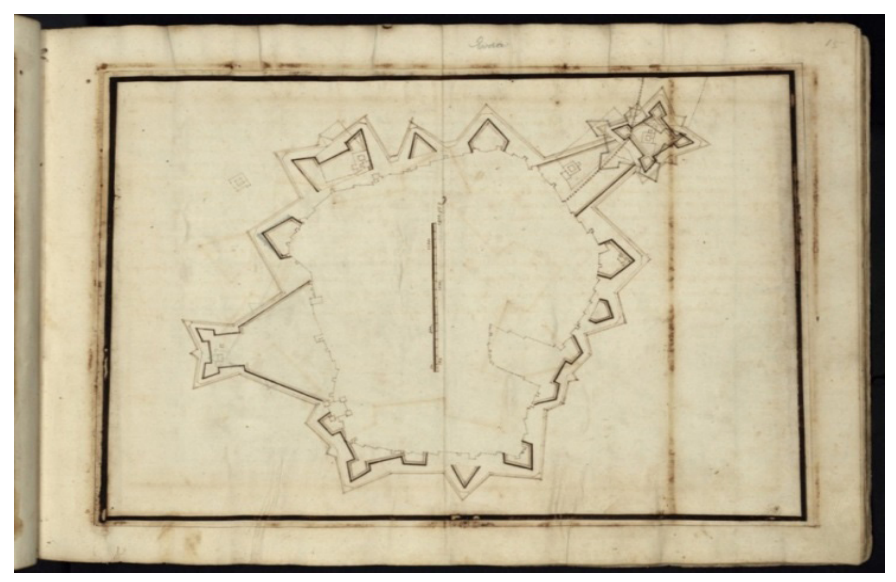

Fuente: Gastão de Melo Mattos, $1956^{57}$.

Además, el esfuerzo y el gasto excesivo del proyecto de Luís Serrão Pimentel no justificarían el mismo. El perfil consistiría en un muro de 30 pies de alto, de parapeto con 24 de espesura y 6 de altura en el interior, con la línea superior inclinada al pie de la contraescarpa (revestimiento externo ante los disparos de la artillería), y el terraplén de la plataforma de maniobras de artillería de 22 pies de altura. Sería un gasto innecesario que llevaría a Évora la ruina.

Ya que el foso era estrecho para el ángulo de las medias lunas y ancho para los lados de los baluartes ${ }^{58}$, Saint-Colombe no entendía cómo se podría defender con éxito la fortificación. Por ejemplo, en la Puerta de Nossa Senhora de Machede uno de los frentes tenía 390 pies, el otro podría tener 365 , y sus paredes laterales tenían 90 pies.

De mais de se não franquearem os baluartes da planta de Luiz Serrão o que faz na Porta de Machede n. ${ }^{\circ} 9$ tem uma das frentes de 390 pés, e outra de 365 medidas que não me mostrará em nenhum autor, e logo os flancos de 90 pés. O baluarte que faz nos P.es da Camp. ${ }^{\text {a tem }} 210$ pés de frente, um flanco de 130, e outro de 160; disporpoções descompassadas e inauditas; logo põe outro

\footnotetext{
${ }^{55}$ Marquês de Sousa, Pedro, Biografia de Luís Serão Pimentel, Lisboa, Academia Militar, 2014, p. 2. «https:// comum.rcaap.pt/handle/10400.26/15605» [consultado el 28 de agosto de 2018].

${ }_{56}^{56}$ Ibídem.

${ }^{57}$ Plano presente en: De Melo Mattos, Gastão, Nicolau de Langres e a sua Obra em Portugal, Lisboa, Comissão de História Militar, 1956.

${ }^{58}$ Serrão Pimentel, Luís, Methodo Lusitanico...op. cit., p. 46.
} 
com 150 pés de frente entre os padres da - camp. ${ }^{a}$ e S. Bartolomeu, e assim os flancos de uns vem a ser maiores que as frentes dos outros; e do mesmo modo são os mais como se pode ver na planta. ${ }^{59}$

Saint-Colombe hace referencia a que el baluarte que Pimentel había proyectado en los Padres da Compañía tenía 210 pies desde la parte delantera, un flanco de 130 pies, y otro de 160 pies. Sin embargo, dibujó otro baluarte de 150 pies desde la parte delantera, entre este y el baluarte de São Bartolomeu, siendo los flancos de uno más grandes que la parte delantera del otro. De acuerdo con Saint-Colombe, los baluartes del proyecto de Pimentel no podían ser aceptados porque tenían una evidente desproporción.

A pesar de la controversia, Luís Serrão Pimentel vio su proyecto aprobado por el Consejo de Guerra. Aunque el plan había sido objeto de una gran cantidad de modificaciones —en el caso especial de la ciudadela-, y a pesar también de estar incompleto, marcó las pautas definitivas para la fortificación de la ciudad de Évora. Además, en virtud del Decreto de 4 de mayo de 1660, se proclamaba la necesidad de reforzarse con urgencia la ciudad ${ }^{60}$.

En los proyectos representados, y después de las campañas de la Guerra de Restauración, entre 1668 y 1669, la ciudad de Évora se presentaba a los visitantes, en relación con sus baluartes defensivos, en la forma en que es presentada por el pintor Pier Maria Baldi (fig. 2). Su ilustración nos muestra una fortificación imponente, pero inacabada.

Figura 2: La fortificación de Évora por Pier Maria Baldi, 1668-1669

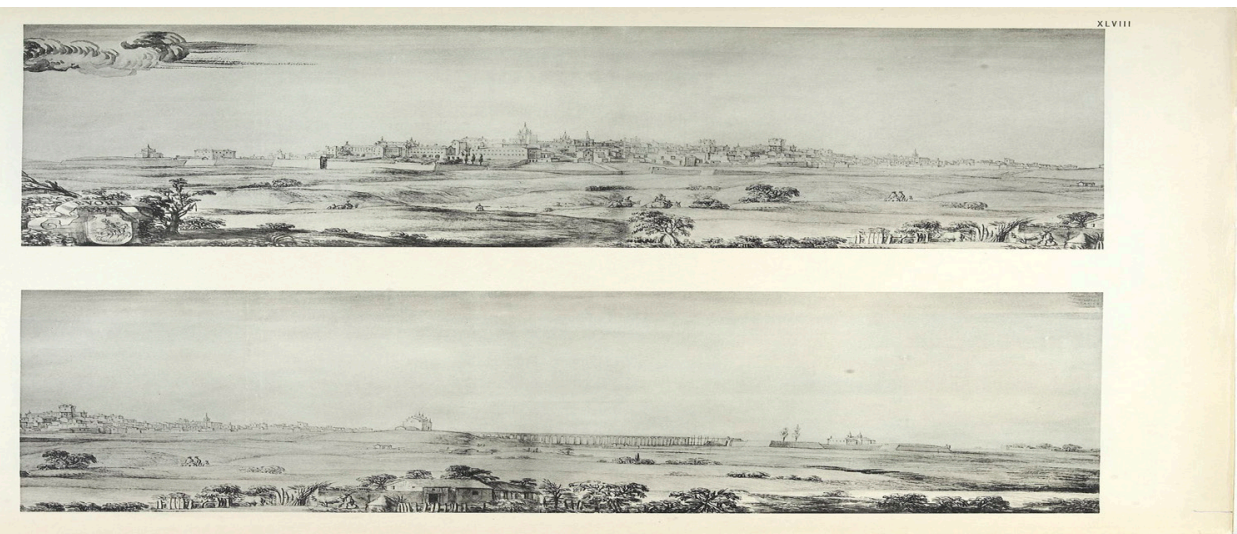

Fuente: Lorenzo Magalotti. ${ }^{61}$

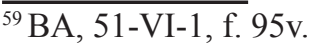

${ }^{60}$ Espanca, Túlio, Inventário Artístico de Portugal - Conselho de Évora, Lisboa, Academia Nacional de BelasArtes, 1966, p. 76.

${ }^{61}$ Magalotti, Lorenzo, Viaje de Cosme de Médicis por España y Portugal (1668-1669), Edición y notas por Ángel Sánchez Rivero y Ángela Mairutti de Sánchez Rivero, Madrid, Sucesores de Rivadeneyra, 1933. «http://purl. pt/12926/1/P52.html» [consultado el 17 de julio de 2018].
} 


\section{La fortificación de Évora: baluartes y fuertes}

Con alguna controversia, según hemos podido constatar, la fortificación de Évora fue tomando forma y se desarrollaron sus cortinas, como podemos ver aún hoy en día en ciertas partes (fig. 3):

La primera conexión se hace en la cortina del jardín público de la ciudad, y conectaba (todavía es así) el Baluarte del Príncipe con el del Conde de Lippe (camino 1-2).

La segunda cortina cubre la Horta das Laranjeiras, y conectaba el Baluarte del Conde de Lippe con el del Picadeiro (camino 2-3).

La tercera conexión se refiere a la zona comprendida entre el Hospital Distrital de Évora y la sede de los Bombeiros Voluntários, y conectaba el Baluarte del Picadeiro con el del Assa (camino 3-4).

La cuarta cortina se apoya en el Hospital Distrital de Évora, que une el Baluarte del Assa al baluarte de Nossa Senhora de Machede (camino 4-5).

De la quinta cortina solo quedan algunos restos pertenecientes al Colegio del Espírito Santo de la Universidad de Évora. Esta hacía de enlace entre el Baluarte de Nossa Senhora de Machede y el Baluarte de los Apóstolos (camino 5-6).

Todavía habría una sexta cortina que conectaría ese Baluarte con el baluarte de São Bartolomeu (camino 6-7) ${ }^{62}$.

Figura 3: Plano del centro urbano de Évora (Municipio de Évora, DCHPC). Circulo rojo, baluartes (de izquierda a derecha): Baluarte del Príncipe, Baluarte del Conde de Lippe, Baluarte del Picadeiro, Baluarte del Assa, Baluarte de Nossa Senhora de Machede, Baluarte de los Apóstolos, Baluarte de São Bartolomeu. Rombo azul, puertas (de izquierda a derecha): Puerta del Raimundo; Puerta del Rossio; Puerta de la Mesquita; Puerta de Nossa Senhora de Machede; Puerta de Avis; Puerta da Lagoa,

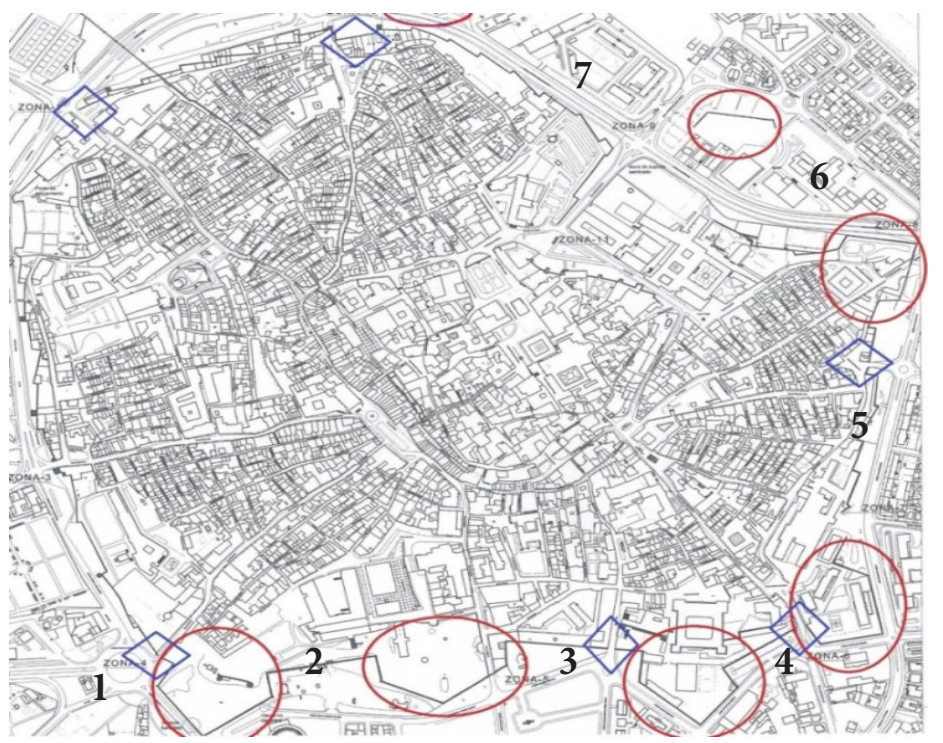

Fuente: Municipio de Évora, Departamento do Centro Histórico, Património e Cultura - adaptado.

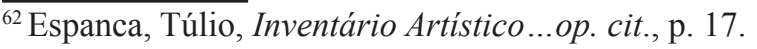


Da porta de Alconchel para a do Roxio, que olha para o caminho de Beja, se levantou hum baluarte [...].Este estava quasi acabado, da porta do Rocio até a de Machede, o qual arco compreende mais que porçaõ de circulo, naõ tinha outra obra, que movida a terra para quatro baluartes: da porta de Machede até a de Aviz estavaõ dous, hum nos primeiros cimentos, \& outro quasi em defença; junto desta porta, bastantemente levantado, estava o baluarte chamado S. Bertholomeu, o qual era franqueado dos dous, que se fabricavaõ na eminencia de Santo Antonio: da porta de Aviz â da Alagoa naõ havia mais obra que huma muralha velha, \& por mais que se quisesse aproveitar destes mubrioens, como estavaõ arrimados aos muros, naõ podiaõ estar desquartinados, porque os torreons, \& cubos da fabrica antigua daquelas cortinas, impediaõ franquearemse estes chamados baluartes. ${ }^{63}$

\subsection{Baluartes}

El Baluarte del Príncipe (fig. 4) es de construcción sólida con esquinas reforzadas de granito, preparado con garitas ejecutadas en mampostería también de granito, con un largo friso saliente que acompaña por el exterior la base de su parapeto. Su construcción se inició en 1651, bajo la asistencia de Langres.

Figura 4: Sección del Baluarte del Príncipe.

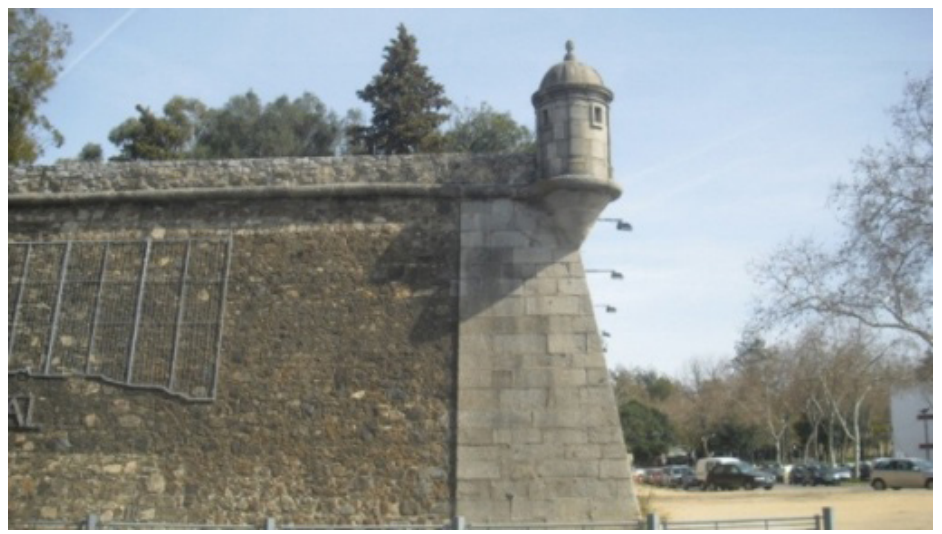

Fuente: Ana Teresa de Sousa, 2012.

La construcción del Baluarte del Conde de Lippe (fig. 5) es coetánea de la última fase de construcción del baluarte anterior, siguiendo una tipología similar. De hecho, está reforzado con granito y tiene tres garitas ejecutadas también en granito. Dada su tipología, se considera obra de Langres, aunque su construcción haya tenido varias fases posteriores a su intervención.

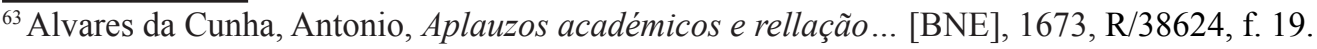


Figura 5: Sección del Baluarte del Conde de Lippe.

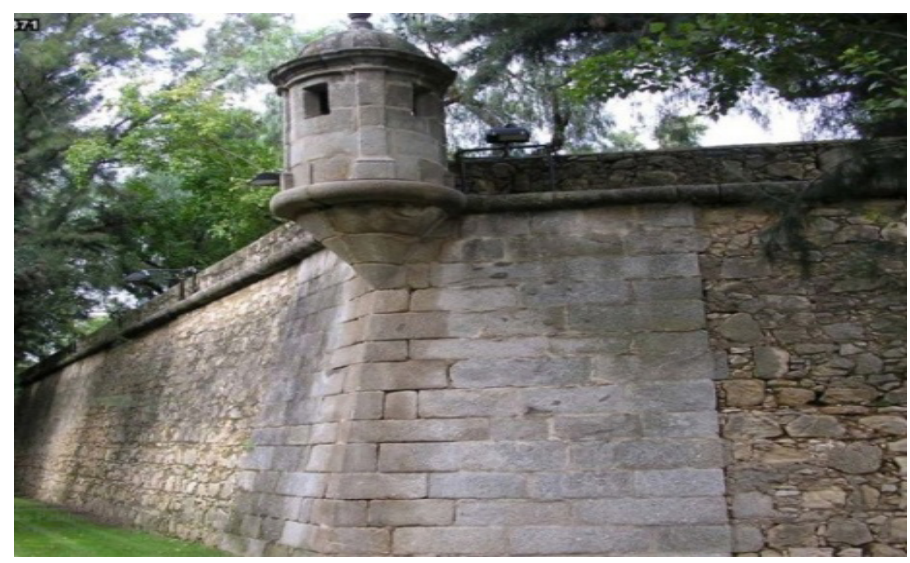

Fuente: Ana Teresa de Sousa, 2012.

El Baluarte del Picadeiro (fig. 6) fue diseñado más adelante por Diogo Pardo Osório, discípulo de Luís Serrão Pimentel, y se levantó en 1680. Así pues, su construcción estaría influenciada por la teoría de Serrão Pimentel. Con tipología constructiva similar a los baluartes anteriores, nos muestra su intervención en la construcción de estos tres.

Figura 6: Sección del Baluarte del Picadeiro. A la derecha detalle de intervención en el cuerpo de la garita.

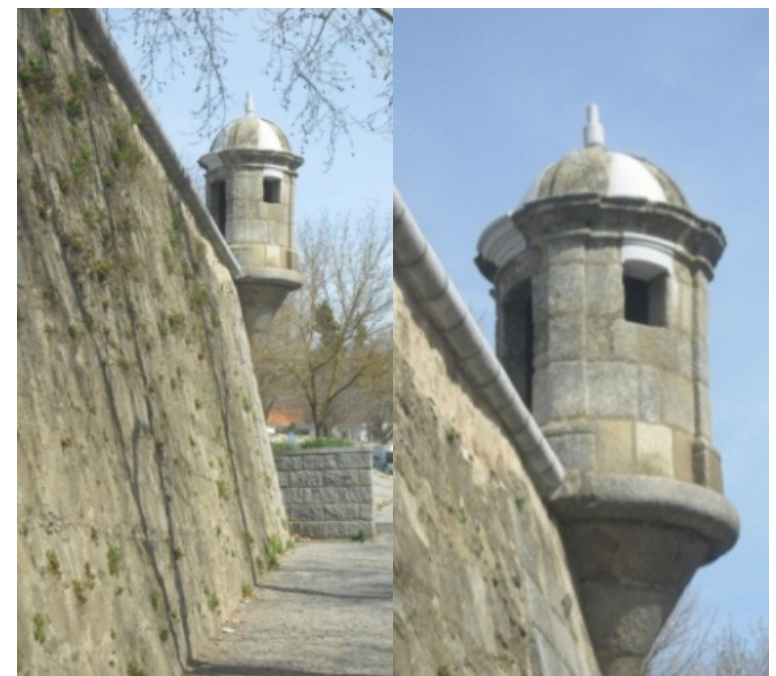

Fuente: Ana Teresa de Sousa, 2012.

El terraplén del Baluarte del Assa (fig. 7) está ocupado por el Hospital Distrital de Évora. Su espacio se ha visto muy alterado debido a sucesivos movimientos y retiradas de tierra causados por obras de urbanización de los alrededores. Además, como puede verse, ya no presenta sus garitas. Su tipología es muy similar a la del Baluarte del Picadeiro, por lo que su construcción por los discípulos de Serrão Pimentel habrá tenido lugar en la misma época. 
Figura 7: Sección del Baluarte del Assa.

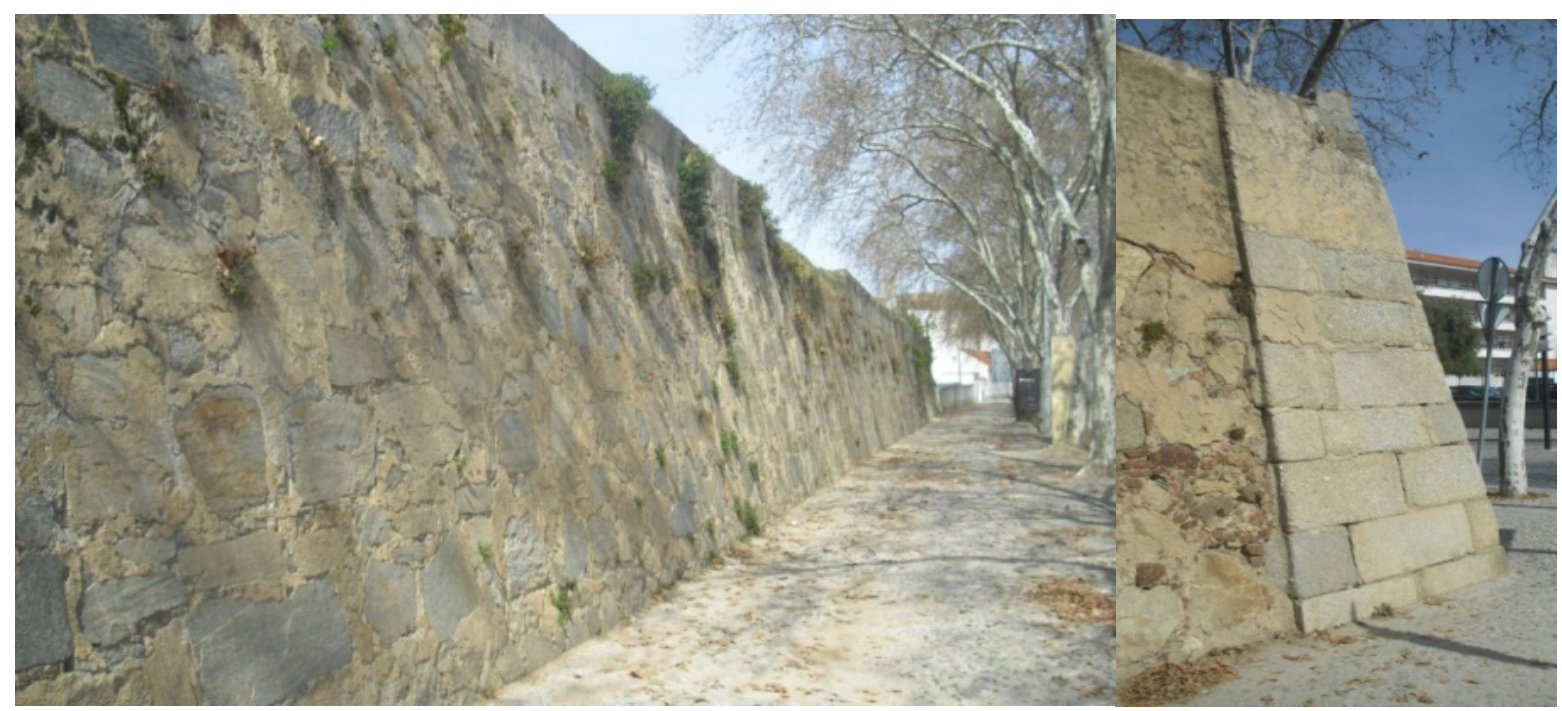

Fuente: Ana Teresa de Sousa, 2012.

La tipología de construcción del Baluarte de Nuestra Señora de Machede (fig. 8) es diferente a la de los otros existentes, pues es notorio el uso de tapia junto con la mampostería de piedra y ladrillo. Esta metodología no se utilizaba ya después de la influencia de Serrão Pimentel. Ejecutado entre 1640 y 1641, tras la inspección de los ingenieros militares franceses Lassart y Gilot, nos muestra que Serrão Pimentel no habría efectuado una gran intervención en este baluarte después de 1661 .

Figura 8: Sección del Baluarte de Nossa Senhora de Machede.

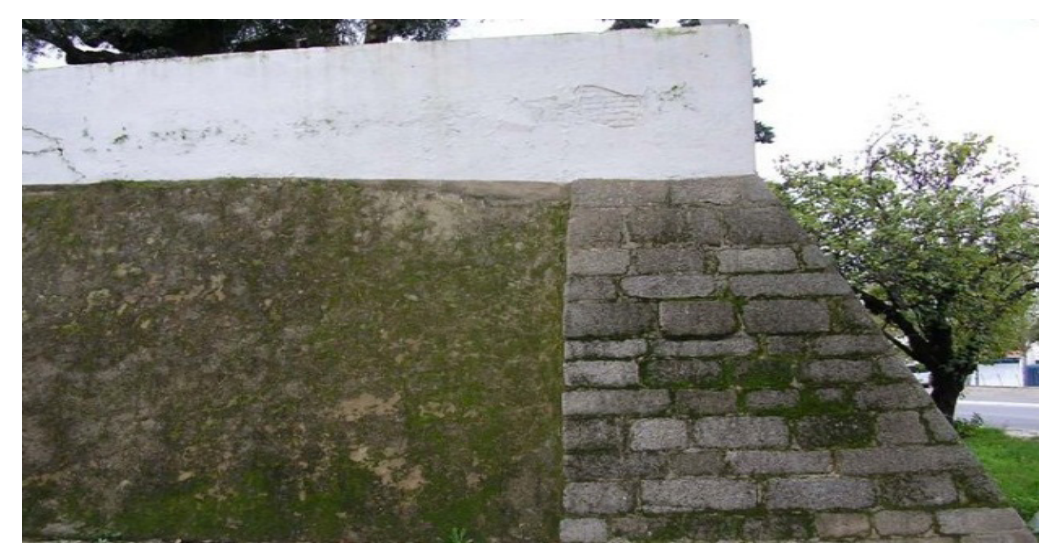

Fuente: Ana Teresa de Sousa, 2012.

El Baluarte de los Apóstolos (fig. 9) protegía el jardín de los Padres de la Compañía. Parte de este baluarte fue diseñado por Saint-Colombe poco después de 1660, teniendo su última fase de construcción en $1680^{64}$. Pero nunca llegaría a completarse ${ }^{65}$.

\footnotetext{
${ }^{64}$ Espanca, Túlio, Inventário Artístico... op. cit., p. 17.

${ }^{65}$ Córtes, Fernando, "Subsídios Documentais para o estudo das fortificações de Évora e de outras Praças militares alentejanas nos inícios da Guerra da Restauração”, en A Cidade de Évora, 67-68 (1984-1985), p. 199.
} 
Figura 9: Sección del Baluarte de los Apóstoles.

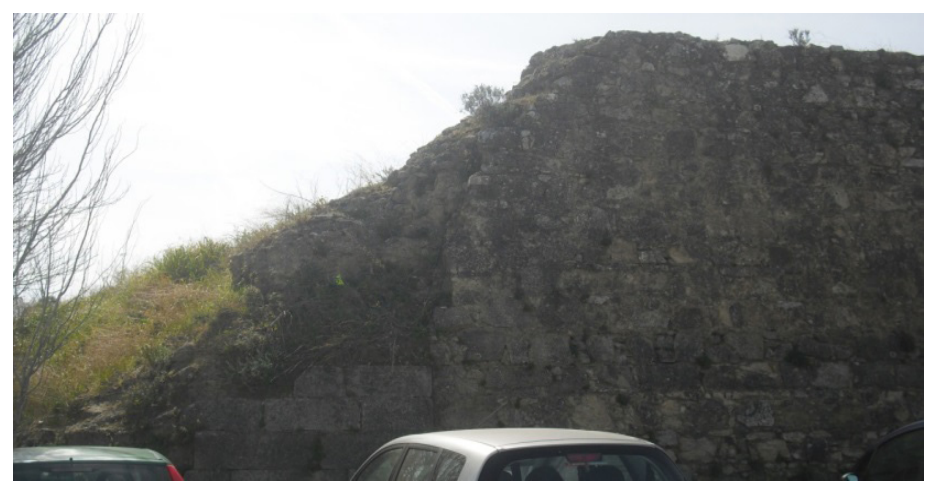

Fuente: Ana Teresa de Sousa, 2012.

Por último, el Baluarte de São Bartolomeu (fig. 10) se compone de un rediente de tres bordes irregulares, que aprovecha la loma natural donde están los restos de la Ermita de São Bartolomeu. Conserva algunos materiales originales de su fundación, ya que fue destruido en los asedios de $1663^{66}$ y se levantó de nuevo después de la publicación del Regimiento de la Fortificación de Évora, en $1682^{67}$, a petición de Pedro II y de la Junta de los Tres Estados ${ }^{68}$.

Figura 10: Sección del Baluarte de São Bartolomeu.

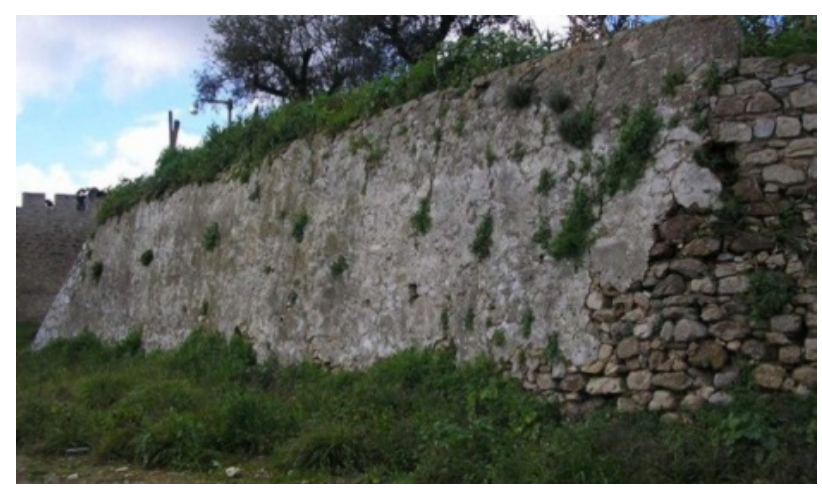

Fuente. Ana Teresa de Sousa, 2012.

\subsection{Fuertes}

\subsubsection{Fuerte de Santo António}

En el año de 1650, el Consejo de Guerra de João IV dio orden para la edificación del Fuerte de Santo António (fig. 11) con el propósito de proteger el Convento de Santo António da Piedade. Su proyecto inicial procede del ingeniero Nicolau de Langres, pero sufriría

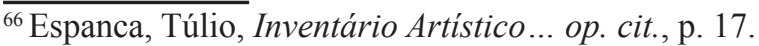

${ }^{67}$ ANTT, Manuscritos da Livraria, n. ${ }^{\circ} 1634$ (58), ff. 239-245.

${ }^{68}$ Espanca, Túlio, "Libertação da cerca amuralhada de Évora”, en A Cidade de Évora, 48-50 (1965-67), p. 173.
} 
modificaciones posteriores por parte del general de Schomberg. No obstante, su plano final fue trazado por el general de artillería Agostinho de Andrade Freire, que lo reformuló después de 1665, quedando listo en la década siguiente bajo la asistencia de Luís Serrão Pimentel.

Destaca su foso y sus diferentes garitas angulares, que lo convierten en un ejemplar único dentro de esta tipología arquitectónica.

Figura 11: Muralla del Fuerte de Santo António de Évora.

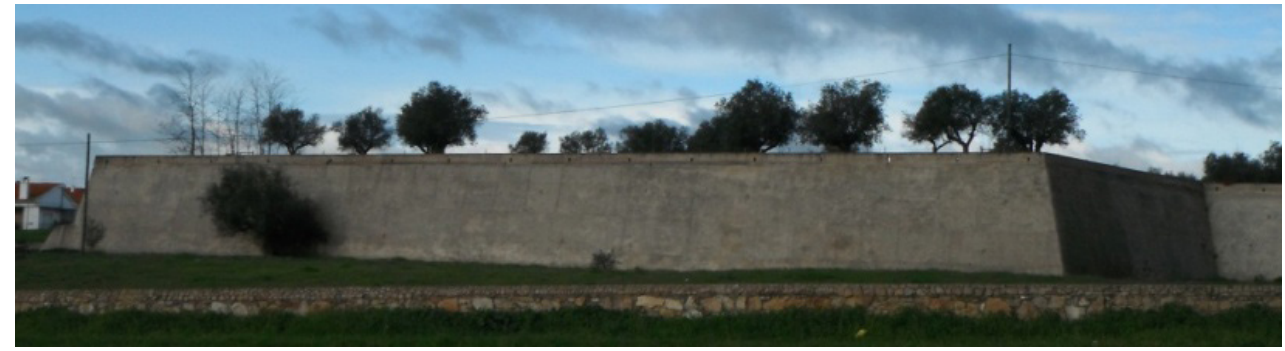

Fuente: Ana Teresa de Sousa, 2012.

Aos vinte \& seis [junio de 1663] sahio devora o Conde de Sartirana seu Governador, pella brecha que se havia feito entre as portas da Alagoa, \& Aviz, com três mil \& duzentos infantes do seu presidio, \& oitocentos \& doze cavallos, que forão entregues ao General da cavalaria Dinis de Mello de Castro (...). No mesmo dia entraram na Cidade triunfantes os Portuguezes. Mandou o de Villaflor pòr em arrecadação para a fazenda de S. Magestade, o que os Castelhanos havião deixado, as obras que tinhão feito na Cidade forão, aperfeiçoar, \& pòr em defensa o Forte de Santo Antonio, huma estrella [... $]^{69}$

\subsubsection{Fuerte de los Penedos}

Se trataba de una obra exterior, cuadrada, de una dimensión muy pequeña con relación al Fuerte de Santo António. Estaba situado cerca de la Puerta del Rossio y del Baluarte del Príncipe, en un punto elevado, y albergaba una guarnición permanente en tiempo de guerra.

A mayor eminencia que a descobre, he hum sitio distante da muralha quinhentos pês, que vulgarmente se chama dos Penedos: o Mosteiro de S. Antonio de Religiosos de S. Francisco Recolletos da Provincia da Piedade, ainda que eminente, distante mil \& seiscentos pês da Cidade; neste sitio pareceo fabricarse huma cidadela, obra que mais brevemente se poderia pôr na perfeiçaõ; a qual começamdose anos antes, naõ tinha mais defensa que a terra, que se havia levantado para dous baluartes, \& sua cortina. Entre este sitio, \& a porta da Alagoa está o Convento dos Carmelitas calçados, cujo edifício se afasta da dita porta duzentos pês, daqui até a porta de Alconchel que olha para o caminho de Lisboa, \& tem diante de si, mas mais vezinho, o Mosteiro dos

\footnotetext{
${ }^{69}$ Álvares da Cunha, António, Aplauzos académicos e rellação... [BNE], 1673, R/38624, ff. 74-75.
} 
Carmelidas descalços; naõ tem mais obra que no sitio das Olarias, a fabrica de huns reductos que se fabricaõ despois da marcha do exercito contrario. ${ }^{70}$

\section{Conclusión}

Aunque el plan de Luís Serrão Pimentel de fortificación de la ciudad de Évora ha sido objeto de una gran cantidad de alteraciones, e incluso ha quedado incompleto, nos ha dado las directrices definitivas para la fortificación de la ciudad.

Sin embargo, fue Pimentel quien actuó como responsable de las obras de fortificación de la ciudad de Évora durante mucho tiempo. Así, a finales de 1660, llegaría a la plaza para cumplir específicamente con sus órdenes el general de artillería Pedro Jaques de Magalhães.

Pero, desde sus inicios, las obras en la fortificación de Évora tuvieron muchos problemas para avanzar debido al poco dinero disponible. Otro de los principales motivos que llevaron a la interrupción de las obras sería el hecho de que el ingeniero militar Nicolau de Langres, en 1662, pasara a servir al enemigo castellano, lo que provocaría un gran cambio de planes en la construcción de esta fortificación, como hemos podido constatar, siguiéndose en última instancia el proyecto de Luís Serrão Pimentel basado en el proyecto inicial de Langres. Esta semejanza es evidente cuando se comparan las figuras 1 y 3 , la primera correspondiente al proyecto de Nicolau de Langres, y la segunda correspondiente al plano del centro urbano de Évora, donde se puede descortinar su fortificación. Aunque no subsista su proyecto en papel, es evidente su similitud. Saint-Colombe se ocupará de señalarloen su Resposta Apologética.

La comparación y/o el desacuerdo entre Luís Serrão Pimentel y Saint-Colombe nos presenta dos concepciones de los medios de fortificación: uno con la teoría y práctica de los conceptos franceses, con obras adelantadas, medias lunas, y el otro basado en las teorías del método portugués de fortificación, de frente continua sin obras exteriores, fruto del estudio de los autores holandeses, más prácticos a la hora de fortificar, y de los aprendizajes que Pimentel tuvo con los jesuitas, unas teorías que se basaban en la aplicación práctica de la matemática y la geometría. Por lo demás, como podemos comprobar en las objeciones, Serrão Pimentel defiende la utilización de medias lunas en la fortificación, pero no la forma en que Saint-Colombe las elaboró en su proyecto, ya que tendrían poca resistencia frente al ataque del enemigo y frente a cambios o cuestiones meteorológicas A ello se añade su notoria indignación frente a la poca profundidad del foso presentada por Saint-Colombe, pues representaba una defensa muy débil de la plaza, pudiendo el enemigo cercarla fácilmente. Aunque Saint-Colombe se hubiera $\overline{{ }^{70} \text { Ibídem, ff. 18-19. }}$ 
defendido con referencia a la profundidad del foso, alegando que se podría hacer más profundo posteriormente, para Serrão Pimentel, seguidor de los métodos de fortificación holandeses, esa opinión representaba una afrenta, pues él era muy consciente de la importancia del foso en una fortificación según lo que había estudiado de los maestros holandeses. Este era el mejor elemento de la fortificación que permitía mantener al enemigo alejado. Además, en situación de ataque ya sería tarde para hacer el foso más profundo, por lo que desde el inicio debería tener la profundidad adecuada.

Mediante el análisis de los dos puntos de vista, y verificando que el proyecto de Serrão Pimentel acabó siendo el elegido, podemos concluir que uno de los motivos podría haber sido precisamente la semejanza comprobada con respecto al proyecto anterior de Langres para la ciudad, pues algunos de los baluartes ya habían sido comenzados por él. Aunque el proyecto de Serrão Pimentel pudiera presentar más perímetro e implicar un mayor gasto monetario, en realidad, fue inteligente hasta el punto de aprovechar elementos que ya estaban construidos, mejorándolos. Por lo tanto, el gasto no sería mayor, al contrario de lo que alegaba Saint-Colombe, ahorrándose, además, tiempo en la obra. En ese contexto, el proyecto de Saint-Colombe se encontraba entonces en desventaja, pues era un plan nuevo que se apartaba de lo anteriormente proyectado para la ciudad. Sabemos que en época de guerra escaseaban el tiempo y el dinero, teniendo que aprovecharse de lo más beneficioso en el momento. Así reveló serlo el proyecto del ingeniero jefe del reino Luís Serrão Pimentel, maestro en matemática y fortificación, consciente de la necesidad de adaptación respecto a lo existente en la ciudad de Évora.

Finalmente, es curioso comprobar que, durante la ocupación de la ciudad de Évora por los castellanos, en junio de 1663, estos hubieran invertido en la mejoría de algunos de los elementos constructivos de esta fortificación, como fue el caso del Fuerte de Santo António, para su propia defensa contra los soldados portugueses. 